\title{
Species-specific performance and trade-off between growth and survival in the early-successional light-demanding group
}

\author{
T.O. VIEIRA*, L.S. SANTIAGO ${ }^{* * * * *}$ (iD) , I.A. PESTANA* (D), E. ÁVILA-LOVERA*** (D), \\ J.L.A. SILVA* (iD , and A.P. VITÓRIA ${ }^{*+}$
}

Universidade Estadual do Norte Fluminense Darcy Ribeiro, Laboratório de Ciências Ambientais, Av. Alberto Lamego, 2000, UENF-CBB, Parque Califórnia, 28013-602 Campos dos Goytacazes, RJ, Brazil ${ }^{*}$

Department of Botany and Plant Sciences, University of California, 2150 Bachelor Hall, Riverside, CA 92521, USA ${ }^{* *}$

Smithsonian Tropical Research Institute, Apartado 0843-03092, Balboa, Panama***

\begin{abstract}
We investigated if high irradiance imposes stress conditions and differently affects the performance of species from the early-successional light-demanding group and if the costs associated with plasticity underlie the trade-off between growth and survival. Survival, growth, chlorophyll $a$ fluorescence, and carbon stable isotopic ratio $\left(\delta^{13} \mathrm{C}\right)$ were measured in seedlings of four tree species in a restoration area in the Atlantic Forest under full-sun exposure and partial shading treatments. The maximal quantum yield of PSII indicated stress conditions mainly in the full-sun exposure treatment (values from 0.72 to 0.81 ). The $\delta^{13} \mathrm{C}$ ranged from -31.9 to $-30.4 \%$, but did not differ between treatments for three species, suggesting that $\mathrm{C}$ assimilation in initial restoration conditions is stressful even in shade. The survival scaled negatively with growth and plasticity adjustments. We conclude that early-successional species do not form a homogenous species group because they differ in functional responses to stress, and phenotypic plasticity, with these variations showing a strong link with the trade-off between growth and survival. This information should be taken into account for species selection in restoration programs.
\end{abstract}

Keywords: biodiversity hotspots; chlorophyll $a$ fluorescence; functional traits; leaf traits; photochemical parameters.

\section{Introduction}

Irradiance is well known for acting as a local environmental filter by restricting the establishment, growth, and reproduction of species depending on their photosynthetic light demands and the ability to adjust functional traits (Bazzaz and Pickett 1980, Silva et al. 2010, Lusk et al. 2011, Rabelo et al. 2013, Mediavilla et al. 2014, Teixeira

\section{Highlights}

- Early-successional species do not form a homogenous group in responses to stress

- Initial restoration conditions can be stressful even in partial shading conditions

- The differentiation in species' performances reveals a continuum of adaptive responses
Received 21 September 2020

Accepted 10 February 2021

Published online 16 March 2021

${ }^{+}$Corresponding author

e-mail: apvitoria@gmail.com

Abbreviations: $\mathrm{C}$ - elemental carbon; $C_{\mathrm{i}}$ - intercellular $\mathrm{CO}_{2}$ concentration; $\mathrm{D}$ - diameter at soil level; $\mathrm{F}_{\mathrm{v}} / \mathrm{F}_{\mathrm{m}}-$ maximal quantum yield of PSII; H - height; LA - leaf area; NL - number of leaves; NPQ - nonphotochemical quenching coefficient; PCA - principal component analysis; $\mathrm{PC} 1$ - first principal component; $\mathrm{PC} 2$ - second principal component; $\mathrm{q}_{\mathrm{P}}$ - photochemical quenching coefficient; RCI - relative chlorophyll index; RDPI - relative distance plasticity index; RGR - relative growth rate; SLA - specific leaf area; $\delta^{13} \mathrm{C}-\mathrm{C}$ stable isotopic ratio.

Acknowledgements: The authors acknowledge the financial support given by FAPERJ (Fundação Carlos Chagas Filho de Amparo à Pesquisa do Estado do Rio de Janeiro - E-26/111.203/2014, E-26/210.064/2018). This study was partially financed by the Coordenação de Aperfeiçoamento de Pessoal de Nível Superior - Brazil (CAPES) - Finance Code 001. The first author thanks the CAPES/Brazil for the Doutorado Sanduíche no Exterior fellowship (PDSE Program - 88881.134771/2016-01). A.P. Vitória thanks the CNPq (Conselho Nacional de Pesquisa e Desenvolvimento Tecnológico, 302330/2019-4) for PQ scholarship. The authors thank Letícia dos Anjos Silva for suggestions and support with analyses of phenotypic plasticity and União Biological Reserve.

Conflict of interest: The authors declare that they have no conflict of interest. 
et al. 2015, 2018; Kardiman et al. 2019). Functional traits are defined as morpho-physio-phenological traits which impact fitness indirectly via their effects on growth, reproduction, and survival, the three components of individual performance (Violle et al. 2007). High irradiance often reduces the leaf's ability to properly maintain the photochemical apparatus, which in turn decreases the net photosynthesis, particularly during the seedling stage (Vitória et al. 2016, Paula et al. 2019).

Plant performance in stressful environments depends on both individual and coordinated adjustments in functional traits (Bongers et al. 2017, Delhaye et al. 2020). For example, high irradiance can improve the carbon gain and favor the plant growth, but it comes at the cost of adjusting several, if not all, leaf traits to avoid photoinhibition (Vieira et al. 2015, Vitória et al. 2016). In addition, high irradiance can increase the need for a high carotenoids (Car)/chlorophyll (Chl) ratio, high dissipation of excess excitation energy and high maximal quantum yield of PSII $\left(\mathrm{F}_{\mathrm{v}} / \mathrm{F}_{\mathrm{m}}\right)$, low specific leaf area, and high discrimination against ${ }^{13} \mathrm{CO}_{2}$ that results in ${ }^{13} \mathrm{C}$-enriched leaf tissues (Farquhar et al. 1989, Demmig-Adams and Adams 1992, Lage-Pinto et al. 2012, Goldstein et al. 2016, Paula et al. 2019). On the other hand, low irradiance can benefit species performance by reducing the costs associated with photoacclimation, although it leads to low growth rates (Vieira et al. 2015, Paula et al. 2019).

Early-successional species evolved to deal with high irradiance, not only due to a particular set of functional traits, such as high dark respiration rate, light-compensation point, light-saturated net photosynthetic rate, and dissipation of excess excitation energy, but also due to higher phenotypic plasticity compared to late successional species (Vitória et al. 2016, Calzavara et al. 2019). Phenotypic plasticity, defined as the ability of an organism to express different phenotypes triggered by environmental variations (Gratani 2014), is assumed to enable beneficial adjustments, particularly in open areas where high irradiance imposes restrictions against several species (Winn 1996, Kenzo et al. 2011). Phenotypic plasticity allows functional adjustments that may increase the species performance in photosynthesis, reproduction, survival, and growth (DeWitt et al. 1998, Valladares et al. 2000, Valladares and Niinemets 2008, Couso and Fernández 2012, dos Anjos et al. 2015, Cerqueira et al. 2018, Silva et al. 2020), although some plasticity adjustments are neutral or may not result in improved performance (van Kleunen and Fischer 2005, Sánchez-Gómez et al. 2006, Ghalambor et al. 2007, Liu et al. 2016). High phenotypic plasticity may also lack beneficial adjustments, and even compromise the survival and growth in stressful environments such as restoration areas (DeWitt et al. 1998, Alpert and Simms 2002, Gianoli and González-Teuber 2005, Valladares et al. 2007, Valladares and Niinemets 2008, Bongers et al. 2017).

In restoration programs around the world, the selection of species is a critical and challenging step that determines their success, particularly in degraded and open areas (Kardiman et al. 2019). This is especially relevant for the Atlantic Forest of South America, which is one of the three biodiversity hotspots most vulnerable to climate change (Myers et al. 2000, Bellard et al. 2014, Scarano et al. 2016), and one of the biomes with high conservation priority (Fontana et al. 2018). In practice, the selection of species is based on their successional status, with an emphasis on two large groups formed by early-successional light-demanding species and late-successional shadetolerant species (Swaine and Whitmore 1988, RedondoBrenes 2007, Rodrigues et al. 2009, 2011; Calzavara et al. 2019). Despite the long tradition of prioritizing the successional status (Bazzaz and Pickett 1980, Chazdon et al. 1996, Strauss-Deberiedetti and Bazzaz 1996), this type of selection ignores that species may differ within the groups and, in fact, the variation among species can be large enough to create a continuum of strategies rather than groups (Goldstein et al. 2016). It suggests that the flexibility in the demand for light is not necessarily related to the successional status (dos Anjos et al. 2015, Goldstein et al. 2016, Cerqueira et al. 2018, dos Santos et al. 2019, Kardiman et al. 2019). A continuum of strategies for the use of light has been observed in seedlings, with the typical pioneers at one end of the continuum and shadetolerant ones at the opposing end (Calzavara et al. 2019). However, it is not entirely clear how photoacclimation and photoplasticity of functional traits may affect the survival and growth of seedlings of light-demanding species at the beginning of the restoration, known as the most susceptible phase of the restoration process (Ruiz-Jaen and Potvin 2011, Martínez-Garza et al. 2013, 2016; Paine et al. 2015).

Here, we carried out an experiment under natural rainfall, air temperature, and photosynthetically active radiation, under full-sun exposure and partial shading treatments, in a restoration area in the Atlantic Forest of South America. The survival and growth rates as well as morphological and physiological leaf traits of four earlysuccessional native species were measured to answer the following questions: (1) Does the irradiance variation impose stress and differently affect the performance of species from the early-successional light-demanding group? (2) Do the costs of phenotypic plasticity underlie the trade-off between growth and survival?

\section{Materials and methods}

Study area, plant material, and experimental design: The study was carried out in a restoration area at the União Biological Reserve, Rio de Janeiro state, Brazil $\left(22^{\circ} 27^{\prime} 30^{\prime \prime} \mathrm{N}, 4^{\circ} 02^{\prime} 15^{\prime \prime} \mathrm{W}\right)$. This Reserve consists of 7,500 ha of preserved Atlantic Forest, and 220 ha of restoration area, which replaced an old eucalyptus plantation (Corymbia citriodora) after forest management programs in 2013. The vegetation is classified as lowland wet forest (Braga et al. 2016). The climate is tropical humid with a dry winter (Aw; Alvares et al. 2013), a mean annual temperature of $25^{\circ} \mathrm{C}$, and a mean annual precipitation of $1,900 \mathrm{~mm}$, concentrated between October and April. The environmental data sets for the experimental period are presented in Fig. 1S (supplement). Air temperature was 
measured in the studied restoration area using a thermohygrometer (910.15, CHH, Alla, Brazil), and rainfall was measured by a manual pluviometer. The restoration area has a gently undulating topography, which varies from the sea level to $370 \mathrm{~m}$ a.s.l. The soil is dystrophic red-yellow podzolic with sandy clay texture (Lima et al. 2011).

Four tree species were selected based on their success to survive as shown in previous restoration programs. It included Vitex polygama Cham., Lamiaceae; Cupania oblongifolia Mart., Sapindaceae; Cytharexylum myrianthum Cham., Verbenaceae; and Guarea guidonia (L.) Sleumer, Meliaceae; all classified as early-successional light-demanding species (Swaine and Whitmore 1988). As the species belong to different genera, generic names were used hereafter to facilitate reading. Seedlings of these species aged between two and three months were purchased from a commercial nursery, which produces seedlings from seeds collected at the São João River hydrographic basin, where the Reserve is located.

Seedlings were planted in an area of 9.7 ha at $2.5 \mathrm{~m}$ apart from each other in December 2014 (rainy season), and then monitored during $210 \mathrm{~d}$ from February to September 2015. Twenty seedlings per species with similar height and number of leaves were randomly selected, marked, and equally divided in two groups to be exposed to full-sun treatment [around 2,000 $\mu \mathrm{mol}$ (photon) $\mathrm{m}^{-2} \mathrm{~s}^{-1}$ ] and partial shading [around $950 \mu \mathrm{mol}$ (photon) $\mathrm{m}^{-2} \mathrm{~s}^{-1}$ ]. Partial shading was achieved by artificial structures made of wooden slats and polyethylene mesh, which were placed right over the seedlings to reduce incident irradiance to levels similar to intermediate canopy understory conditions. The PPFD was measured using a quantum sensor coupled with a light meter (Li-190 and Li-250A, Li-Cor Biosciences, Lincoln, Nebraska, USA).

Survival, growth, and morphological traits: The counting of alive seedlings, analyses of growth and morphological traits were carried out eight times in intervals of $30 \mathrm{~d}$ from time zero to the end of the experiment $\left(\mathrm{T}_{0}, \mathrm{~T}_{30}, \mathrm{~T}_{60}, \mathrm{~T}_{90}\right.$, $\mathrm{T}_{120}, \mathrm{~T}_{150}, \mathrm{~T}_{180}$, and $\mathrm{T}_{210}$ ). For each interval, the growth was measured through the increment in height $(\mathrm{H}[\mathrm{cm}])$, diameter at soil level (D [cm]), and number of leaves (NL), and estimated by the slope of simple linear regressions between $\mathrm{H}, \mathrm{D}$, and NL as response variables, and the time as predictor. Relative growth rate (RGR) was calculated for $\mathrm{H}, \mathrm{D}$, and $\mathrm{NL}$ at each interval, as: $\mathrm{RGR}=\left(\ln H_{1}-\ln H_{0}\right) /$ $\left(t_{1}-t_{0}\right)$, where $H_{0}$ and $H_{1}$ were initial and final values, and $t_{0}$ and $t_{1}$ were initial and final measurement times.

Morphological traits included the total leaf area (LA $\left[\mathrm{cm}^{2}\right]$ ), specific leaf area (SLA $\left.\left[\mathrm{cm}^{2} \mathrm{~g}^{-1}\right]\right)$, and the relative Chl index (RCI). They were measured in two healthy and fully expanded leaves of ten individuals per species and treatment. Leaves were scanned with a metric scale and had the area estimated by the software Image $J 1.46 \mathrm{r}$ (https://imagej.nih.gov/ij/). Then, leaves were oven-dried at $60^{\circ} \mathrm{C}$ for $72 \mathrm{~h}$ to obtain the dry mass. Specific leaf area was obtained by the ratio between LA and dry mass (PérezHarguindeguy et al. 2013). Relative Chl index was taken using a portable chlorophyll meter (SPAD-502, Minolta, Japan).
Chl $\boldsymbol{a}$ fluorescence: Chl $a$ fluorescence was measured at the beginning and end of the experiment in four individuals per species, and two healthy and fully expanded leaves per individual, always in the third pair (Vitória et al. 2016). The measurements were carried out at 7:00 h using a portable modulated light fluorometer (FMS2, Hansatech, UK). Leaves were dark-adapted for $30 \mathrm{~min}$ prior to the measurements using leaf clamps, and then exposed to weak, modulated beam of approximately $6 \mu \mathrm{mol}($ photon) $\mathrm{m}^{-2} \mathrm{~s}^{-1}$ at $660 \mathrm{~nm}$, followed by highly-intense actinic white light $\left[10,000 \mu \mathrm{mol}\right.$ (photon) $\left.\mathrm{m}^{-2} \mathrm{~s}^{-1}\right]$ during $0.8 \mathrm{~s}$ (Genty et al. 1989). The physiological traits were maximal quantum yield of PSII $\left(\mathrm{F}_{\mathrm{v}} / \mathrm{F}_{\mathrm{m}}\right)$, photochemical quenching $\left(\mathrm{q}_{\mathrm{P}}\right)$, and nonphotochemical quenching (NPQ) coefficients.

Carbon stable isotopic analyses: At the end of the experiment, the carbon stable isotopic ratio $\left(\delta^{13} \mathrm{C}\right)$ was determined for two fully expanded leaves in the third pair, with little to no sign of damage, for four seedlings per species per treatment. Leaves were oven-dried at $60^{\circ} \mathrm{C}$ for at least two days and grounded to fine powder. The elemental carbon, and carbon isotopic composition in samples of approximately $1 \mathrm{mg}$ were measured by a continuous flow elemental analyzer (Flash 2000 Organic Elemental Analyzer, Thermo Fisher Scientific, Germany) coupled to a stable isotope ratio mass spectrometer (IRMS Delta V Advantage, Thermo Fisher Scientific, Germany). Pee Dee Belemnite (PDB) was used as a standard for carbon analyses. The analytical precision was $\pm 0.1 \%$ o for $\delta^{13} \mathrm{C}$, and the accuracy for elemental and isotopic compositions were determined by certified standard (Protein OAS/Isotope Cert 114859, Elemental Microanalysis).

Data analyses: All statistical analyses were carried out in the $R$ software (R Core Team 2019). Phenotypic plasticity was analyzed individually for $\mathrm{H}, \mathrm{D}, \mathrm{NL}, \mathrm{SLA}, \mathrm{RCI}, \mathrm{F}_{\mathrm{v}} / \mathrm{F}_{\mathrm{m}}$, $\mathrm{q}_{\mathrm{P}}, \mathrm{NPQ}$, and $\delta^{13} \mathrm{C}$ for each species using the relative distance plasticity index (RDPI), which varies from zero to one and allows the comparison of traits with distinct units (Valladares et al. 2006). It was calculated by the rdpi function of the 'Plasticity' package (Ameztegui 2017). To avoid biased interpretations from multiple comparisons, a general RDPI for each species was calculated as the sum of all RDPI values. Then, the general RDPI was standardized by the highest observed value to scale the variation from zero to one. Finally, the general RDPI was modeled as a function of time for each species using cubic and quartic polynomial fits, by the $l m$ and poly functions of the 'base' package (R Core Team 2019). The adjusted multiple coefficient of determination, and the associated $p$-values were reported.

To evaluate how much species differed in survival, growth, morphological, and physiological traits when submitted to irradiance treatments (question one), several analyses of covariance ( $A N C O V A \mathrm{~s}$ ) were performed using the general RDPI as predictor and time as the covariable. $A N C O V A$ s were run by the $g l m$ function of the 'base' package (R Core Team 2019). Data were transformed using the maximum likelihood by the boxcox function 
of 'MASS' package (Venables and Ripley 2002) to meet assumptions of normality, linearity, and homoscedasticity of residuals. If no effect was observed for the covariable, then models were updated to test differences in survival, growth, or general RDPI over the time only. Multiple comparisons among species were performed using the Tukey's correction by the emmeans function of the 'emmeans' package (Lenth 2020).

To evaluate the cost associated with plasticity and its impact on species performance (question two), the survival and growth ratios between the full-sun exposure and partial shading treatments were related to the general RDPI through a generalized linear model, using the $\mathrm{glm}$ function of the 'base' package. The explanatory power of models was obtained as the residual deviance divided by the null deviance minus one.

A principal component analysis (PCA) was run to confirm the clustering of species based on survival, growth, morphological, and physiological traits. Variables were $z$-scaled (i.e., standard deviation of one and mean of zero) to avoid the influence of different units on the formation of clusters. The PCA was run using the ggbiplot function of the 'ggbiplot' package (Vu 2011). Ellipses were plotted in two PCA dimensions to group species, considering one standard deviation from ellipses centroid ( $68 \%$ confidence interval) ( $\mathrm{Vu}$ 2011). The percentage of overlap among ellipses measured the differences between species, and it was calculated by the maxLikOverlap function of the 'SIBER' package (Jackson et al. 2011).

\section{Results}

Physiological traits: Despite the absence of statistical difference, the $\mathrm{F}_{\mathrm{v}} / \mathrm{F}_{\mathrm{m}}$ values indicated stress conditions at $T_{0}$ and $T_{210}$ for both treatments, although the majority of the lowest values were observed at $T_{210}$ under full-sun exposure (Fig. 1, Table 1). For all species, the partial shading treatment showed the highest $F_{v} / F_{m}$ values. The $\mathrm{q}_{\mathrm{P}}$ values were higher than 0.91 . All the NPQ values were below 0.18 , with the highest values being recorded for Vitex at the partial shading treatment.

For all species, Chl was higher under partial shading (RCI values ranged from 34.23 to 45.95 ) than under full-sun exposure (from 26.54 to 35.18 ) (Table 1). The irradiance treatments did not change the $\delta^{13} \mathrm{C}$ for Vitex, Cupania, and Guarea (values ranged from -30.40 to $-31.93 \%$ ), but Cytharexylum had ${ }^{13} \mathrm{C}$-enriched leaves under the full-sun exposure (Table 1).

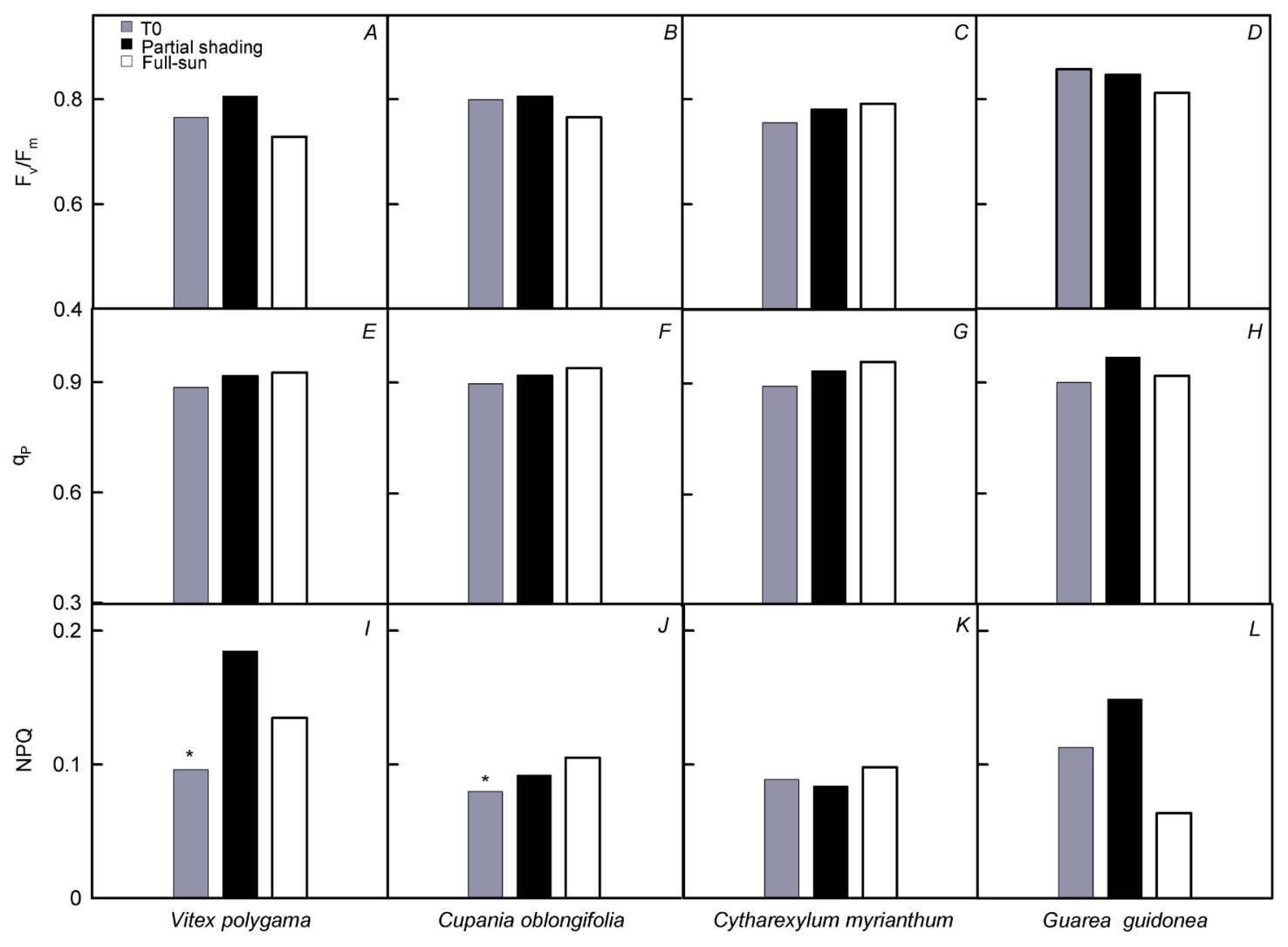

Fig. 1. Maximal quantum yield of PSII $\left(\mathrm{F}_{\mathrm{v}} / \mathrm{F}_{\mathrm{m}}\right)(A-D)$, photochemical quenching $\left(\mathrm{q}_{\mathrm{P}}\right)(E-H)$, and nonphotochemical quenching (NPQ) $(I-L)$ measured at 7:00 $\mathrm{h}$ before establishing the experiment in situ $\left(\mathrm{T}_{0}\right)$ and at the end of the experiment $(210 \mathrm{~d})$ in full-sun exposure and partial shading treatments. Vitex polygama $(A, E, I) ;$ Cupania oblongifolia $(B, F, J) ;$ Cytharexylum myrianthum $(C, G, K)$; Guarea guidonia $(D, H, L)$ in the União Biological Reserve, Brazil. Values are means, $n=4$. Statistical analyses in Table $1 \mathrm{~S}$ (supplement). * Compare treatments $(p \leq 0.05)$. 
Plant performance: In the PCA based on survival and growth rates over time, two principal components explained $91.4 \%$ of the total variance. The PC1 explained $72.7 \%$ of the total variation and was influenced by NL and the number of surviving seedlings, mostly because of the Cytharexylum performance. The PC2 explained $18.7 \%$ of the remaining variation, with this axis being associated with $\mathrm{H}$ and D (Fig. 2A), and more suitable to separate the species Vitex, Guarea, and Cupania. In the PCA based on morphological and physiological traits measured at the end of experiment (Fig. 2B), two principal components explained $57.8 \%$ of the total variance. The PC1 explained $35.1 \%$ and was directly influenced by morphological traits (e.g., SLA) and the photosynthetic apparatus status $\left(\mathrm{F}_{\mathrm{v}} / \mathrm{F}_{\mathrm{m}}\right.$ and RCI). The PC2 explained $22.7 \%$ of the remaining variation and was associated with photochemical traits $\left(\mathrm{q}_{\mathrm{P}}\right.$, NPQ, and $\delta^{13} \mathrm{C}$ ) (Fig. 2B). The overlapping areas between ellipses distinguished the specific performances and traits and highlighted the particularities of Cytharexylum for both set of data (Fig. 2). Cupania and Guarea species had narrower ellipses than the two other species, which indicate greater constancy in traits variance (Fig. 2).

Survival and growth: Seedling survival decreased over time in a nonlinear decay for both full-sun exposure and partial shading treatments, but the magnitude of decrease was species-specific: Cytharexylum $>$ Guarea $>$ Cupania $>$ Vitex (Fig. 3). The only exception was related to Cytharexylum in the partial shading treatment due to the survival of all seedlings (Fig. 3; Table 1S, supplement). However, seedling survival was from 6 to $23 \%$ higher under partial shading than under full-sun exposure. Pairto-pair comparisons did not reveal differences in survival between species under the partial shading treatment, but differences were observed for Vitex - Cytharexylum, VitexGuarea, and Cytharexylum - Cupania under the full-sun exposure treatment (Table 2S, supplement).

The seedling growth in $\mathrm{H}, \mathrm{D}$, and $\mathrm{NL}$ increased over time in a nonlinear way for most species in both treatments, but the magnitude of increase was speciesspecific and tended to be higher under partial shading than that under full-sun exposure (Fig. 4, Table 1; Tables 1S, $3 \mathrm{~S}$, supplement). Guarea had the second highest growth rate among species under full-sun exposure, but it had one of the lowest growth rates under partial shading (Fig. 4, Tables 1S, 3S).

Photoplasticity: The investment in plastic adjustments over the time in $\mathrm{H}, \mathrm{D}, \mathrm{NL}, \mathrm{SLA}, \mathrm{RCI}, \mathrm{F}_{\mathrm{v}} / \mathrm{F}_{\mathrm{m}}, \mathrm{q}_{\mathrm{P}}, \mathrm{NPQ}$, and $\delta^{13} \mathrm{C}$, measured through the individual RDPI (Table 4S, supplement) and general RDPI, was overall low among traits for Cupania, Cytharexylum, and Guarea, with values ranging from 0.2 to $0.4 \%$ (Fig. 5). However, Vitex showed a high general RDPI, which ranged from 0.2 to $0.8 \%$. All models showed nonlinear significant fits.

The trait plasticity was negatively related to the seedling survival and growth for all species, showing a nonlinear decay over time (Fig. 6, Table 4S). Vitex was the species with the highest plasticity among the four species and able to maintain high survival for a longer period 


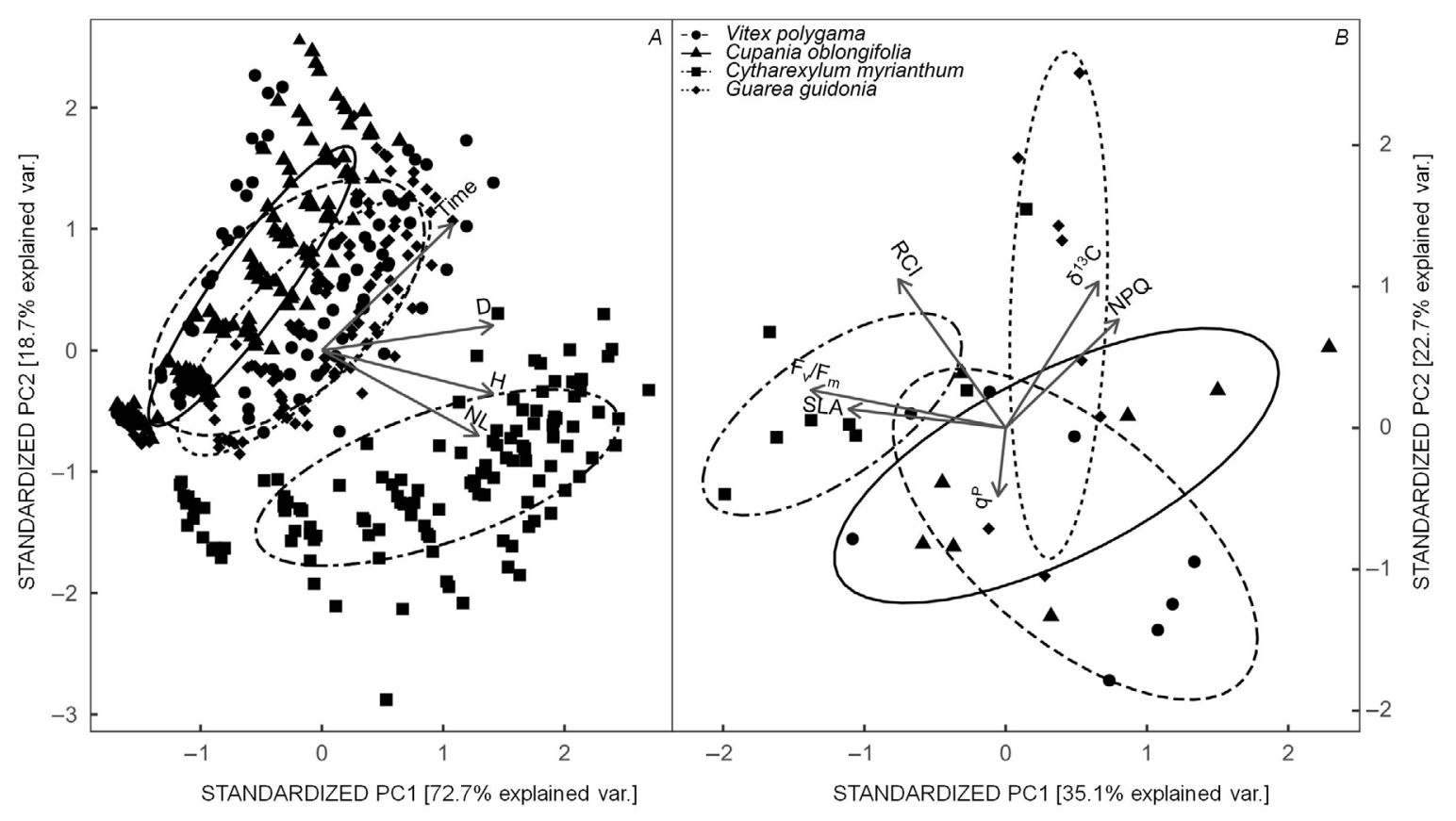

Fig. 2. Principal component analysis (PCA) considering: $(A)$ the values of $\mathrm{H}$ - height; $\mathrm{D}$ - diameter at ground level; NL - number of leaves; and Time - eight intervals of $30 \mathrm{~d}$ for $210 \mathrm{~d}$ in full-sun exposure and partial shading treatments, and $(B)$ the values of SLA specific leaf area; RCI - relative chlorophyll index; $\mathrm{F}_{\mathrm{v}} / \mathrm{F}_{\mathrm{m}}$ - maximal quantum yield of PSII; $\mathrm{q}_{\mathrm{P}}$ - photochemical quenching and NPQ nonphotochemical quenching coefficients; $\delta^{13} \mathrm{C}$ - carbon stable isotopic ratio in full-sun exposure and partial shading treatments at the end of experiment (210 d). Vitex polygama (dashed line, circle), Cupania oblongifolia (solid line, triangle), Cytharexylum myrianthum (dot-dashed line, square), and Guarea guidonia (dotted line, diamond).

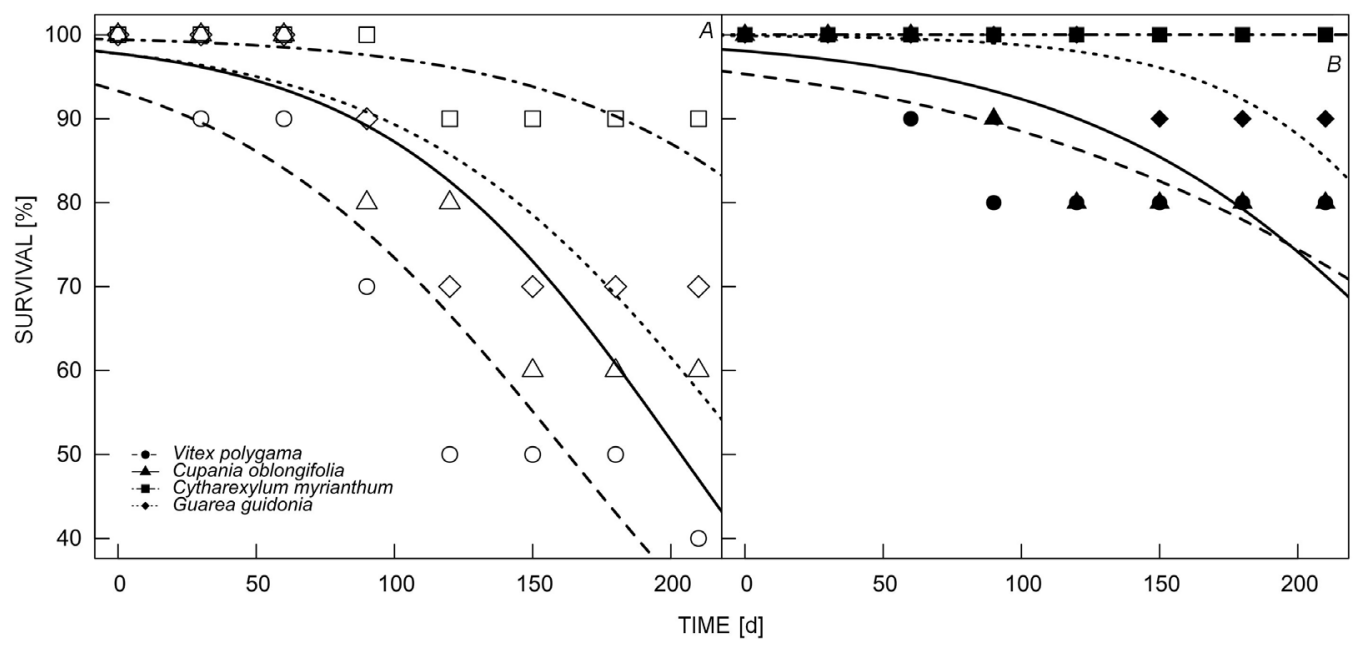

Fig. 3. Seedling survival under $(A)$ full-sun exposure, and $(B)$ partial shading over $210 \mathrm{~d}$ (from February to September 2015) in the União Biological Reserve, Brazil. Vitex polygama (dashed line, circle), Cupania oblongifolia (solid line, triangle), Cytharexylum myrianthum (dot-dashed line, square), and Guarea guidonia (dotted line, diamond). Values are means, $n=10$.

when compared to Guarea. However, Vitex presented the lowest growth ratios (sun/shade) in a diameter and number of leaves (Fig. 6C,D).

\section{Discussion}

Our results suggest species-specific performance within the early-successional light-demanding group, with $F_{v} / F_{m}$ values indicating stress conditions for some species, $\delta^{13} \mathrm{C}$ variation suggesting that the initial restoration condition can be stressful even in partial shading conditions for water-use efficiency, as well as a trade-off between growth and survival. In addition, there were interspecific variations in seedling survival, growth, morphological, and physiological plasticity in response to irradiance for these species, which have been commonly used for 


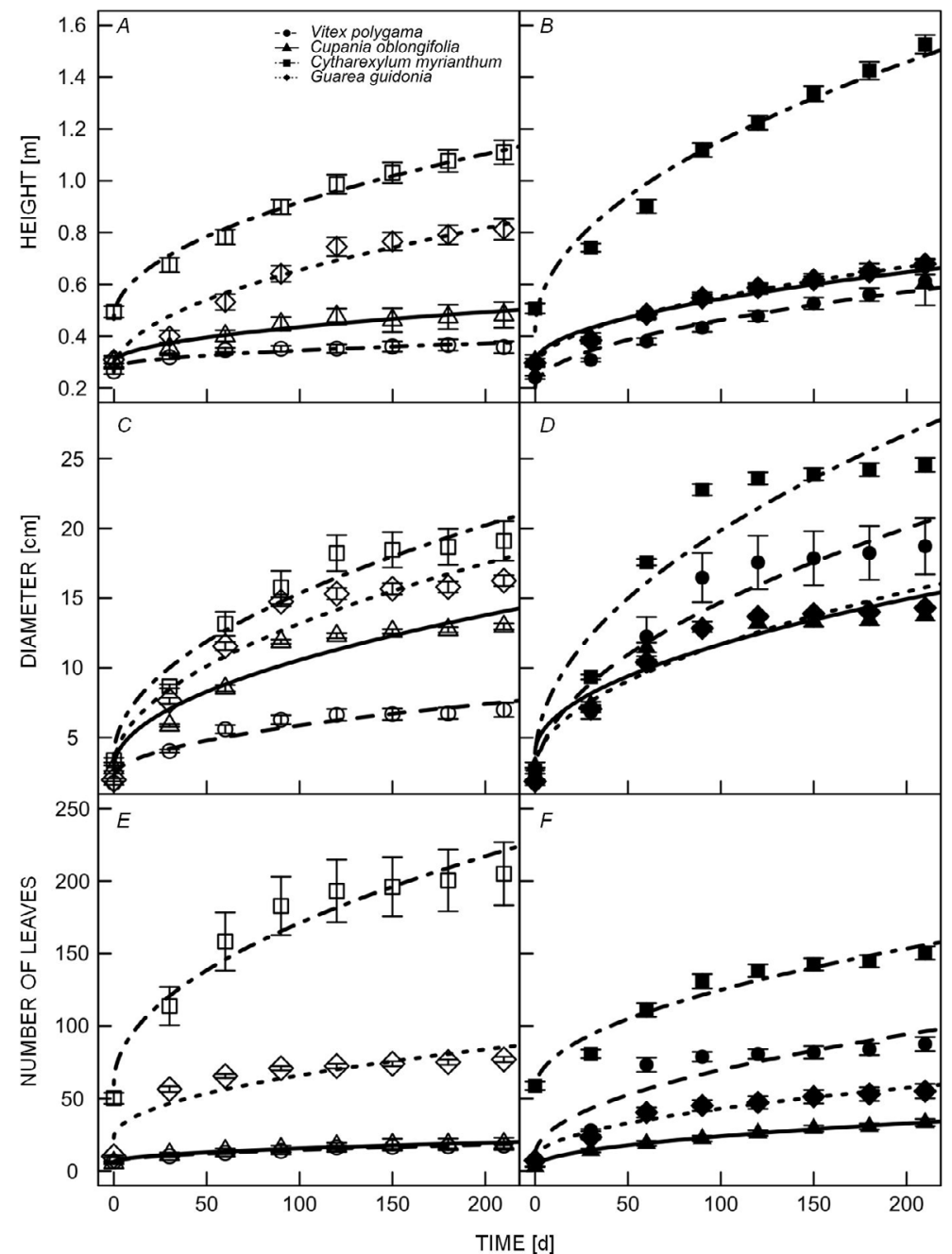

Fig. 4. Rate of growth in height $(A, B)$, diameter $(C, D)$, and number of leaves $(E, F)$ in full-sun exposure $(A, C, E$ - open symbols) and partial shading ( $B, D, F$ - closed symbols) over $210 \mathrm{~d}$ (from February to September 2015) in União Biological Reserve, Brazil. Vitex polygama (dashed line, circle), Cupania oblongifolia (solid line, triangle), Cytharexylum myrianthum (dot-dashed line, square), and Guarea guidonia (dotted line, diamond). Values are means $\pm \mathrm{SD}$, $n=10$.

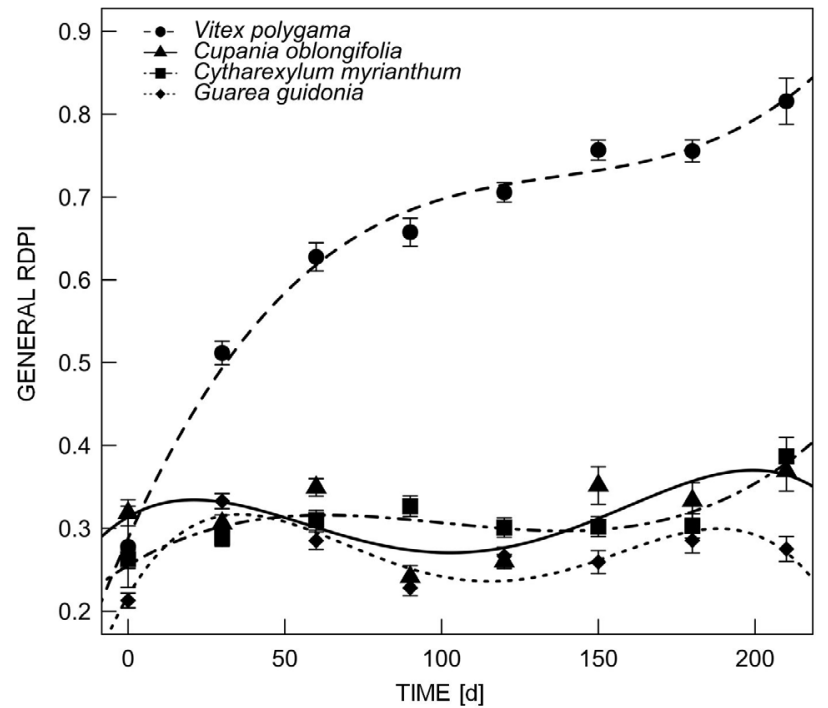

the restoration of the Atlantic Forest in South America. The differentiation in species' performances reveals a continuum of adaptive responses that change over the time (Ellis et al. 2000, Gilbert et al. 2006). In tropical forests,
Fig. 5. General relative distance plasticity index (general RDPI) based on the values of RDPI for survival, $\mathrm{H}$ - height; D diameter at ground level; NL - number of leaves; SLA - specific leaf area; RCI - relative chlorophyll index; $F_{\mathrm{v}} / \mathrm{F}_{\mathrm{m}}-$ maximal quantum yield of PSII; $\mathrm{q}_{\mathrm{p}}$ - photochemical quenching and NPQ - nonphotochemical quenching coefficients; $\delta^{13} \mathrm{C}$ - carbon stable isotopic ratio over $210 \mathrm{~d}$ (from February to September 2015 ) in the União Biological Reserve, Brazil. Vitex polygama (dashed line, circle), Cupania oblongifolia (solid line, triangle), Cytharexylum myrianthum (dot-dashed line, square), and Guarea guidonia (dotted line, diamond). Values are means $\pm \mathrm{SD}$, $n=4-10$.

the continuum of strategies in the use of light often results from significant horizontal and vertical heterogeneity in light availability (Domingues et al. 2005, Vieira et al. 2015, Vitória et al. 2019). Even seedlings of neotropical 


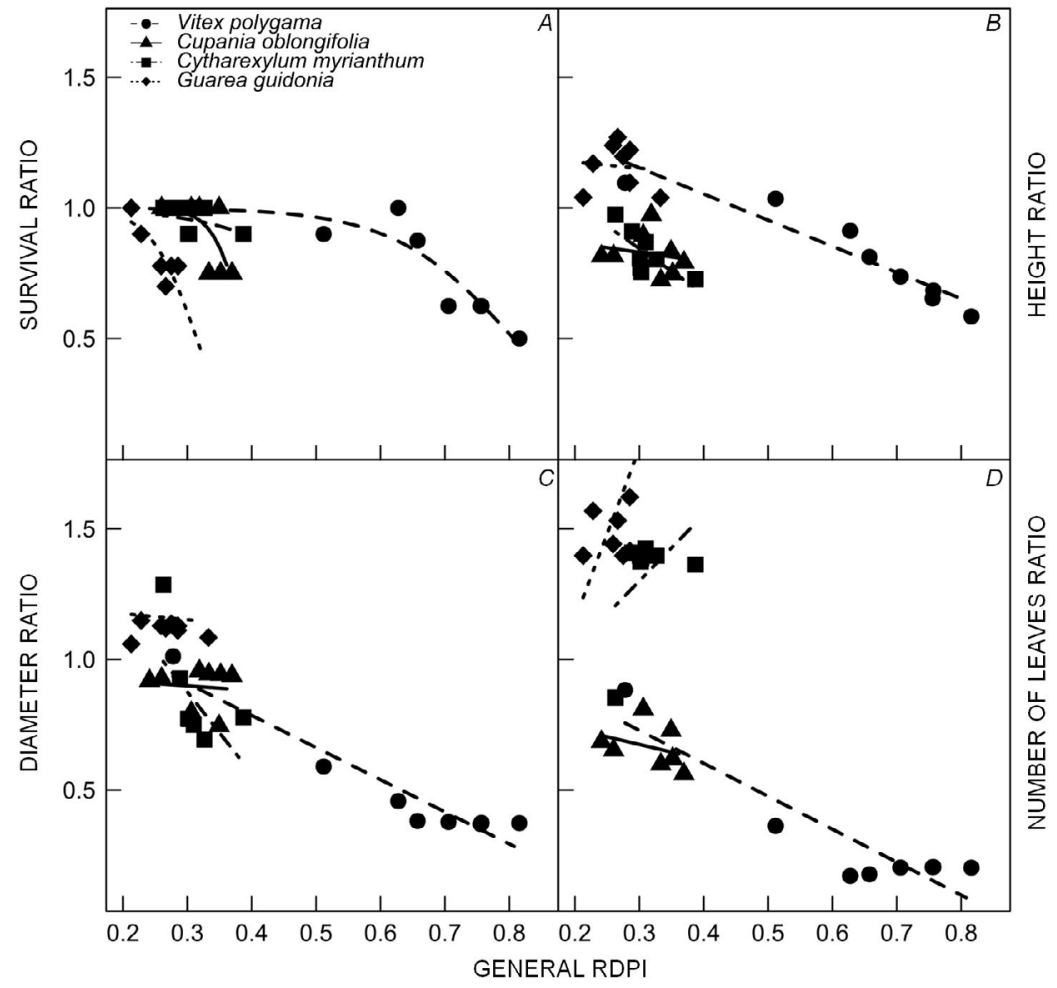

Fig. 6. Association between the capacity of species to have plastic adjustments, measured through the general relative distance plasticity index (general RDPI), and the sun/shade ratios of seedling survival and growth. Vitex polygama (dashed line, circle), Cupania oblongifolia (solid line, triangle), Cytharexylum myrianthum (dotdashed line, square), and Guarea guidonia (dotted line, diamond). tree species show a continuum of light requirements, although these differences are usually discussed in terms of the successional status (Calzavara et al. 2019).

The $F_{v} / F_{m}$ of some species was negatively affected by high irradiance, suggesting the effectiveness of $F_{v} / F_{m}$ for distinguishing species more vulnerable to full-sun exposure from those that can improve the photochemical conditions under partial shading. $\mathrm{F}_{\mathrm{v}} / \mathrm{F}_{\mathrm{m}}$ has been used as an indicator of physiological efficiency (BolhàrNordenkampf et al. 1989, Lüttge 2008, Vitória et al. 2016, Paula et al. 2019), with values above 0.8 reflecting optimal operation of the photosynthetic apparatus (Lüttge 2008). However, some authors are less restrictive on this regard, and consider photoinhibition when $\mathrm{F}_{\mathrm{v}} / \mathrm{F}_{\mathrm{m}}$ is below 0.75 (Bolhàr-Nordenkampf et al. 1989). Photoinhibition occurs when the light intensity exceeds the leaf capacity to use it in photosynthesis and/or thermal dissipation (Takahashi and Murata 2008). Photoinhibition and stress conditions according to $F_{v} / F_{m}$ were mostly observed in the full-sun exposure treatment. However, when we evaluated the RDPI for each parameter, it was low for $\mathrm{q}_{\mathrm{p}}$ and $\mathrm{F}_{\mathrm{v}} / \mathrm{F}_{\mathrm{m}}$ for all species, indicating that species were able to acclimate to both irradiance treatments. This capacity was possibly caused by the adjustments in energy dissipation as heat, as suggested by the RDPI for NPQ. NPQ is associated with heat energy dissipation and considered a protection mechanism against the excess of light in the photosynthetic apparatus, helping maintain the efficiency of photosynthetic functioning (Demmig-Adams and Adams 1992, Rabelo et al. 2013, Paula et al. 2019). Another mechanism to avoid light damage was the reduction of Chl content, a strategy observed in plants under high irradiance to avoid photooxidation (Zhang et al. 2018, Vitória et al. 2019).

In addition to $F_{v} / F_{m}$, the differentiation in species' performance can also be observed through the efficiency of water use, assessed by $\delta^{13} \mathrm{C}$ (Farquhar and Richards 1984). Among all species, Guarea displayed the highest photosynthetic water-use efficiency. However, it did not reflect advantages for survival or growth, since Cytharexylum had the lowest $\delta^{13} \mathrm{C}$ values and was the species with the highest survival rate. The $\delta^{13} \mathrm{C}$ has been used to evaluate the acclimation to irradiance as a time-integrated response of photosynthesis in field conditions (Zimmerman and Ehleringer 1990, Dawson et al. 2002, Vitória et al. 2016). However, differently from photochemical evaluations, the irradiance treatments did not promote significant changes in the $\delta^{13} \mathrm{C}$ values, except for Cytharexylum. It has been observed that shading conditions promote ${ }^{13} \mathrm{C}$-impoverishment compared to full sun conditions (Vitória et al. 2016). This suggests restriction of stomatal opening regardless of irradiance treatments in the present study, possibly due to the studied period (dry season) and the restrictive conditions at the beginning of the restoration program. The supply of $\mathrm{CO}_{2}$ at the site of Rubisco carboxylation determines discrimination against ${ }^{13} \mathrm{CO}_{2}$ relative to ${ }^{12} \mathrm{CO}_{2}$ during photosynthesis (Farquhar and Richards 1984). Under high irradiance conditions and water restriction, photosynthesis depends strongly on the intercellular $\mathrm{CO}_{2}$ concentration $\left(C_{\mathrm{i}}\right)$, which releases the discrimination against ${ }^{13} \mathrm{CO}_{2}$ and results in ${ }^{13} \mathrm{C}$-enriched tissue (Farquhar et al. 1989, Vitória et al. 2016, 2018).

Differences in survival between species were observed between the full-sun exposure and partial shading treat- 
ments, which demonstrate that even light-demanding species respond positively to a reduction of $60 \%$ in irradiance. Species performance showed that trait combinations can exhibit trade-offs of photosynthetic and ecological strategies that relate to growth in the restoration process (Ellis et al. 2000, Gilbert et al. 2006, Goldstein et al. 2016). In addition, results corroborate the light functional classification of species in the early-successional category (Björkman 1981, Kitajima 1994, 1996; StraussDeberiedetti and Bazzaz 1996, Valladares et al. 2000, Cai et al. 2005, Portes et al. 2010) but emphasize the vulnerability of species selection based only on functional classification, because it does not consider the interspecific variability within the functional group.

Plasticity adjustments are responsible for establishing limits between preferences and tolerances (Valladares and Niinemets 2008) and it was measured in this study by the RDPI. It was able to show distinct photoacclimation capacities between species. The greatest investments in plasticity were found for morphological traits in the construction of leaf tissue (LA and SLA), with plasticity being negatively related to survival and growth, mainly in the full-sun exposure treatment. It can be understood as a strategy to invest part of the resources in the construction of new structures to maintain and maximize the use of high irradiance (Violle et al. 2007, Rosado et al. 2013). The greater plasticity in morphological traits than that in physiological traits across the studied species is in contrast to to the results of Bongers et al. (2017), who pointed out that physiological traits are more plastic due to regulatory mechanisms that make them more easily adjustable to irradiance variation. However, it is important to highlight that our data were obtained for seedlings, a stage of development that under favorable conditions grows intensely and constantly. Thus, the new leaves produced in the partial shading treatment showed structural changes in order to deal with new environmental conditions since the beginning of its ontogeny, differing from the leaf structures produced in the full-sun exposure treatment.

One of the most notable results in this study was that plastic responses appear to have a cost for the species performances and paying this cost unfavored some of them. We constructed 'norm reaction-type' graphs to represent how phenotypes change in response to irradiance variation over the time, with slopes of the relationships representing the strength of phenotypic plasticity. The results revealed a negative relationship between plasticity and survival, indicating a cost for growth. In this regard, the general RDPI showed great differences between Vitex and all the other species, which supported the hypothesis of species-specific performance associated with functional amplitude and the cost for plasticity adjustments. Our results not only suggested that the high plasticity observed for the Vitex species in response to irradiance variation was passive, but also that it was maladaptive. Passive plasticity responses are not necessarily adaptive and can involve maladaptive responses, while active plasticity can enhance phenotype adjustments to increase the fitness (Smith-Gill 1983, Parsons et al. 2020). We assumed that phenotypic plasticity is an advantage for the species when it increases their fitness, and thereby considered as active (or adaptive) (Muth and Pigliucci 2007, Smith-Gill 1983, van Kleunen et al. 2011, Valladares et al. 2014). Although plastic adjustments have been verified, some plastic responses may not have a positive effect on the fitness or even reduce it, being considered as neutral and maladaptive responses, respectively (van Kleunen and Fischer 2005, SánchezGómez et al. 2006, Ghalambor et al. 2007, Liu et al. 2016).

In contrast to Vitex, Cytharexylum exhibited a lower plasticity and more efficient performance in both irradiance treatments in comparison to all species. The observed performance corroborates the pattern revealed by the ellipses in the PCA analyses. The survival-growth tradeoff found in our study is consistent with the leaf economic scheme based on allocation patterns, in which investments to enhance growth may come at the cost of restricting allocation to traits related to survival and plasticity (Kitajima 1994, 1996; Westoby et al. 2002, Wright et al. 2004, 2010; Reich et al. 2006, Sánchez-Gómez et al. 2006). This survival-growth trade-off characterizes the cost associated with plasticity adjustments based mainly on morphological traits, as observed elsewhere (Wright and Sutton-Grier 2012, Rosado et al. 2013, dos Anjos et al. 2015, Bongers et al. 2017). Contrary to the regeneration under an intact forest canopy, where growth and survival are often negatively correlated with irradiance (Kitajima and Poorter 2008, Silva et al. 2020), our data were collected above $40 \%$ of full irradiance, simulating open area conditions. Greater growth in shaded conditions is likely related to the stem elongation effect, where elongation occurs in response to low irradiance as a strategy to intercept more irradiance (Weinig and Delph 2001).

We expected changes in species plasticity over time, and it was possible to identify two groups, distinguished by extreme and intermediate performances. The first group was formed by Vitex and Cytharexylum, which showed extreme performances (low and high, respectively) that remained constant over the time. The cubic and polynomial fits on the data of Vitex and Cytharexylum suggest predictable performance along two response peaks (investment in plasticity adjustments) related to inflection points. These results indicate the competitive advantage of Cytharexylum and its ability to establish at the beginning of the restoration process (Stratton and Goldstein 2001, Ewe and Sternberg 2003, 2005). This species has a large functional niche amplitude, which corresponds to a more generalist performance. In contrast, Vitex showed a contrasting performance, with narrower niche and low restoration potential, although it presented a wider plasticity than the other species. In that sense, we suggest that Vitex should not be used at the beginning of plantings. These results reveal the two extremes in the continuum of responses within the group of light-demanding species and the high influence of plasticity to improve restoration success. The second group formed by Guarea and Cupania suggest an intermediate investment in plasticity related to short and long-term adjustability. The polynomial fit on the data of these species directly reflects their greater ability to adjust distinct responses to environmental variability 
over time. The quartic polynomial fit indicates four points of inflection. In this sense, Guarea and Cupania revealed niche amplitudes that corroborate their restoration potentials, as well as their persistence in the understory. We suggest that Guarea and Cupania could be used in initial plantings or different stages of the restoration process. The occurrence of two mathematical functions in the discretion of species performance highlights the heterogeneity of response within the functional group of early-successional light-demanding species.

We conclude that species from the same successional status and growing under similar irradiance conditions were able to differ in their responses to stress, performance, and phenotypic plasticity. It was more evident under high irradiance, which imposed stress condition for some species and required greater requirements in plasticity, whereas low irradiance conditions released species from phenotypic adjustments. In addition, we were able to demonstrate that the costs associated with phenotypic plasticity promoted a trade-off between growth and survival, particularly greater for morphological than physiological traits. In this sense, our results provide a baseline for justifying the close relationship between photosynthetic traits and seedling performance of the early-successional species, and their influences on the success of restoration programs. Our approach suggested that the success for restoration of tropical rain forests can be improved by the selection of species with a higher cost effectiveness in plasticity. We emphasize, however, that these recommendations are related to seedlings under natural conditions of establishment.

\section{References}

Alpert P., Simms E.L.: The relative advantages of plasticity and fixity in different environments: when is it good for a plant to adjust? - Evol. Ecol. 16: 285-297, 2002.

Alvares C.A., Stape J.L., Sentelhas P.C. et al.: Köppen's climate classification map for Brazil. - Meteorol. Z. 22: 711-728, 2013.

Ameztegui A.: Plasticity: An R package to determine several plasticity indices. Git Hub repository, 2017.

Bazzaz F.A, Pickett S.T.A.: Physiological ecology of tropical succession: a comparative review. - Annu. Rev. Ecol. Syst. 11: $287-310,1980$.

Bellard C., Leclerc C., Leroy B. et al.: Vulnerability of biodiversity hotspots to global change. - Global Ecol. Biogeogr. 23: 13761386, 2014.

Björkman O.: Response to different quantum flux densities. In: Lange O.L., Nobel P.S., Osmond C.B., Ziegler H. (ed.): Physiological Plant Ecology. Pp. 57-107. Springer, BerlinHeidelberg 1981.

Bolhàr-Nordenkampf H.R., Long S.P., Baker N.R. et al.: Chlorophyll fluorescence as a probe of the photosynthetic competence of leaves in the field: a review of current instrumentation. - Funct. Ecol. 3: 497-514, 1989.

Bongers F.J., Olmo B., Lopez-Iglesias N.P.R. et al.: Drought responses, phenotypic plasticity and survival of Mediterranean species in two different microclimatic sites. - Plant Biol. 19: 386-395, 2017.

Braga N.S., Vitória A.P., Souza G.M. et al.: Weak relationships between leaf phenology and isohydric and anisohydric behavior in lowland wet tropical forest trees. - Biotropica 48 : 453-464, 2016.

Cai Z.-Q., Rijkers T., Bongers F.: Photosynthetic acclimation to light changes in tropical monsoon forest wood species differing in adult stature. - Tree Physiol. 25: 1023-1031, 2005.

Calzavara A.K., Bianchini E., Pimenta J.A. et al.: Photosynthetic light-response curves of light-demanding and shade-tolerant seedlings of neotropical tree species. - Photosynthetica 57: 470-474, 2019.

Cerqueira A.F., Dalmolin A.C., dos Anjos L. et al.: Photosynthetic plasticity of young plants of Carpotroche brasiliensis (Raddi) A. Gray, Achariaceae. - Trees-Struct. Funct. 32: 191-202, 2018.

Chazdon R.L., Pearcy R.W., Lee D.W., Fetcher N.: Photosynthetic response of tropical forest plants to contrasting light environments. - In: Mulkey S.S., Chazdon R.L., Smith A.P. (ed.): Tropical Forest Plant Ecophysiology. Pp. 5-55. Springer, Boston 1996.

Couso L.L., Fernández R.J.: Phenotypic plasticity as an index of drought tolerance in three Patagonian steppe grasses. - Ann. Bot.-London 110: 849-857, 2012.

Dawson T.E., Mambelli S., Plamboek A.H. et al.: Stable isotopes in plant ecology. - Annu. Rev. Ecol. Syst. 33: 507-559, 2002.

Delhaye G., Bauman D., Séleck M. et al.: Interspecific trait integration increases with environmental harshness: A case study along a metal toxicity gradient. - Funct. Ecol. 34: 14281437, 2020.

Demmig-Adams B., Adams III W.W.: Photoprotection and other responses of plants to highlight stress. - Annu. Rev. Plant Phys. 43: 599-626, 1992.

DeWitt T.J., Sih A., Wilson D.S.: Costs and limits of phenotypic plasticity. - Trends Ecol. Evol. 13: 77-81, 1998.

Domingues T.F., Berry J.A., Martinelli L.A.etal.: Parameterization of canopy structure and leaf-level gas exchange for an eastern Amazonian tropical rain forest (Tapajós National Forest, Pará, Brazil). - Earth Interact. 9: 1-23, 2005.

dos Anjos L., Olivia M.A., Kuki K.N. et al.: Key leaf traits indicative of photosynthetic plasticity in tropical tree species. - Trees-Struct. Funct. 29: 247-258, 2015.

dos Santos O.O, Mendes K.R., Martins S.V.C. et al.: Physiological parameters and plasticity as key factors to understand pioneer and late successional species in the Atlantic Rainforest. - Acta Physiol. Plant. 41: 145, 2019.

Ellis A.R., Hubbell S.P., Potvin C.: In situ field measurements of photosynthetic rates of tropical tree species: a test of the functional group hypothesis. - Can. J. Bot. 78: 1336-1347, 2000.

Ewe S.M.L., Sternberg L.S.L.: Seasonal gas exchange characteristics of Schinus terebinthifolius in a native and disturbed upland community in Everglades National Park Florida. Forest Ecol. Manag. 179: 27-36, 2003.

Ewe S.M.L., Sternberg L.S.L.: Growth and gas exchange responses of Brazilian pepper (Schinus terebinthifolius) and native South Florida species to salinity. - Trees-Struct. Funct. 19: 119-128, 2005.

Farquhar G.D., Ehleringer J.R., Hubick K.T.: Carbon isotope discrimination and photosynthesis. - Annu. Rev. Plant Physiol. 40: 503-537, 1989.

Farquhar G.D., Richards R.A.: Isotopic composition of plant carbon correlates with water-use efficiency of wheat genotypes. - Aust. J. Plant Physiol. 11: 539-552, 1984.

Fontana C., Pérez-de-Lis G., Nabais C.: Climatic signal in growth-rings of Copaifera lucens: An endemic species of a Brazilian Atlantic Forest hotspot, southeastern Brazil. Dendrochronologia 50: 23-32, 2018.

Genty B., Briantais J.M., Baker N.R.: The relationship between 
the quantum yield of photosynthetic electron transport and quenching of chlorophyll fluorescence. - BBA-Gen. Subjects 990: 87-92, 1989.

Ghalambor C.K., McKay J.K., Carroll S.P., Reznick D.N.: Adaptive versus non-adaptive phenotypic plasticity and the potential for contemporary adaptation in new environments. Funct. Ecol. 21: 394-407, 2007.

Gianoli E., González-Teuber M.: Environmental heterogeneity and population differentiation in plasticity to drought in Convolvulus chilensis (Convolvulaceae). - Evol. Ecol. 19: 603-613, 2005.

Gilbert B., Wright S.J., Muller-Landau H.C. et al.: Life history trade-offs in tropical trees and lianas. - Ecology 87: 12811288, 2006.

Goldstein G., Santiago L.S., Campanello P.I. et al.: Facing shortage or excessive light: How tropical and subtropical trees adjust their photosynthetic behavior and life history traits to a dynamic forest environment. - In: Goldstein G., Santiago L.S. (ed.): Tropical Tree Physiology: Adaptations and Responses in a Changing Environment. Pp. 319-336. Springer, Cham 2016.

Gratani L.: Plant phenotypic plasticity in response to environmental factors. - Adv. Bot. 2014: 208747, 2014.

Jackson A.L., Inger R., Parnell A.C., Bearhop S.: Comparing isotopic niche widths among and within communities: SIBER - Stable Isotope Bayesian Ellipses in R. - J. Ecol. 80: 595-602, 2011.

Kardiman R., Afriandi R., Schmidt L.H. et al.: Restoration of tropical rain forest success improved by selecting species for specific microhabitats. - Forest Ecol. Manag. 434: 235-243, 2019.

Kenzo T., Yoneda R., Matsumoto Y. et al:: Growth and photosynthetic response of four Malaysian indigenous tree species under different light conditions. - J. Trop. For. Sci. 23: 271-281, 2011.

Kitajima K.: Relative importance of photosynthetic traits and allocation patterns as correlates of seedling shade tolerance of 13 tropical trees. - Oecologia 98: 419-428, 1994.

Kitajima K.: Ecophysiology of tropical tree seedlings. - In: Mulkey S.S., Chazdon R.L., Smith A.P. (ed.): Tropical Forest Plant Ecophysiology. Pp. 559-596. Springer, Boston 1996.

Kitajima K., Poorter L.: Functional basis for resource niche partitioning by tropical trees. - In: Carson W.P., Schnitzer S.A. (ed.): Tropical Forest Community Ecology. Pp. 161-181. Blackwell Publishing, Oxford 2008.

Lage-Pinto F., Bernini E., Oliveira J.G. et al.: Photosynthetic analyses of two native Atlantic Forest species in regenerative understories of eucalyptus plantation. - Braz. J. Plant Physiol. 24: 95-106, 2012.

Lenth R.: emmeans: Estimated Marginal Means, aka LeastSquares Means. R package version 1.5.0, 2020.

Lima J.A. de S., Villela D.M., Calderano Filho B.C., Pérez D.V.: [Fine roots biomass in fragments of Atlantic Forest from Rio de Janeiro State.] - Floresta 41: 27-38, 2011. [In Portuguese]

Liu Y., Dawson W., Prati D. et al.: Does greater specific leaf area plasticity help plants to maintain a high performance when shaded? - Ann. Bot.-London 118: 1329-1336, 2016.

Lusk C.H., Pérez-Millaqueo M.M., Piper F.I., Saldaña A.: Ontogeny, understorey light interception and simulated carbon gain of juvenile rainforest evergreens differing in shade tolerance. - Ann. Bot.-London 108: 419-428, 2011.

Lüttge U.: Physiological Ecology of Tropical Plants. Pp. 458. Springer-Verlag, Berlin 2008.

Martínez-Garza C., Bongers F., Poorter L.: Are functional traits good predictors of species performance in restoration plantings in tropical abandoned pastures? - Forest Ecol.
Manag. 303: 35-45, 2013.

Martínez-Garza C., Campo J., Ricker M., Tobón W.: Effect of initial soil properties on six-year growth of 15 tree species in tropical restoration plantings. - Ecol. Evol. 6: 8686-8694, 2016.

Mediavilla S., Herranz M., González-Zurdo P., Escudero A.: Ontogenetic transition in leaf traits: a new cost associated with the increase in leaf longevity. - J. Plant Ecol. 7: 567-575, 2014.

Muth N.Z., Pigliucci M.: Implementation of a novel framework for assessing species plasticity in biological invasions: responses of Centaurea and Crepis to phosphorus and water availability. - J. Ecol. 95: 1001-1013, 2007.

Myers N., Mittermeier R.A., Mittermeier C.G. et al.: Biodiversity hotspots for conservation priorities. - Nature 403: 853-858, 2000.

Paine C.E.T., Amissah L., Auge H. et al.: Globally, functional traits are weak predictors of juvenile tree growth, and we do not know why. - J. Ecol. 103: 978-989, 2015.

Parsons K.J., McWhinnie K., Pilakouta N., Walker L.: Does phenotypic plasticity initiate developmental bias? - Evol. Dev. 22: 56-70, 2020.

Paula S.M., Boselli M.A., Sanches M.C.: Chlorophyll fluorescence and initial growth of two liana species, Cuspidaria sceptrum (Cham.) L.G. Lohmann and Fridericia florida (DC) L.G. Lohmann, under changes of natural light conditions. Photosynthetica 57: 170-180, 2019.

Pérez-Harguindeguy N., Díaz N.S., Garnier E. et al:: New handbook for standardised measurement of plant functional traits worldwide. - Aust. J. Bot. 61: 167-234, 2013.

Portes M.T., Damineli D.S.C., Ribeiro R.V. et al.: Evidence of higher photosynthetic plasticity in the early successional Guazuma ulmifolia Lam. compared to the late successional Hymenaea courbaril L. grown in contrasting light environments. - Braz. J. Biol. 70: 75-83, 2010.

$\mathrm{R}$ Core Team: R: A language and environment for statistical computing. R Foundation for Statistical Computing, Vienna, Austria, 2019.

Rabelo R.G., Vitória Â.P., Silva M.V.A. et al.: Structural and ecophysiological adaptations to forest gaps. - Trees-Struct. Funct. 27: 259-272, 2013.

Redondo-Brenes A.: Growth, carbon sequestration, and management of native tree plantations in humid regions of Costa Rica. - New Forest. 34: 253-268, 2007.

Reich P.B., Tjoelker M.G., Machado J.-L., Oleksyn J.: Universal scaling of respiratory metabolism size and nitrogen in plants. Nature 439: 457-461, 2006.

Rodrigues R.R., Gandolfi S., Nave A.G. et al.: Large-scale ecological restoration of high-diversity tropical forests in SE Brazil. - Forest Ecol. Manag. 261: 1605-1613, 2011.

Rodrigues R.R., Lima R.A.F., Gandolfi S., Nave A.G.: On the restoration of high diversity forests: 30 years of experience in the Brazilian Atlantic Forest. - Biol. Conserv. 142: 1242$1251,2009$.

Rosado B.H.P., Dias A.T.C., Mattos E.A.: Going back to basics: importance of ecophysiology when choosing functional traits for studying communities and ecosystems. - Nat. Conservação 11: 15-22, 2013.

Ruiz-Jaen M.C., Potvin C.: Can we predict carbon stocks in tropical ecosystems from tree diversity? Comparing species and functional diversity in a plantation and a natural forest. New Phytol. 189: 978-987, 2011.

Sánchez-Gómez D., Valladares F., Zavala M.A.: Performance of seedlings of Mediterranean woody species under experimental gradients of irradiance and water availability: trade-offs and evidence for niche differentiation. - New Phytol. 170: 795- 
806, 2006.

Scarano F.R., Ceotto P., Martinelli G.: Climate change and "campos de altitude": forecasts, knowledge and action gaps in Brazil. - Oecol. Aust. 20: 139-144, 2016.

Silva A.A.D.S., Alvarez M.R.D.V., Mariano-Neto E., Cassano C.R.: Is shadier better? The effect of agroforestry management on small mammal diversity. - Biotropica 52: 470-479, 2020.

Silva A.S, Oliveira J.G, Da Cunha M., Vitória A.P.: Photosynthetic performance and anatomical adaptations in Byrsonima sericea DC. under contrasting light conditions in a remnant of the Atlantic forest. - Braz. J. Plant Physiol. 22: 245-254, 2010.

Smith-Gill S.J.: Developmental plasticity: Developmental conversion versus phenotypic modulation. - Am. Zool. 23: 47-55, 1983.

Stratton L.C., Goldstein G.: Carbon uptake, growth and resource use efficiency in one invasive and six native Hawaiian dry forest tree species. - Tree Physiol. 21: 1327-1334, 2001.

Strauss-Deberiedetti S., Bazzaz F.A.: Photosynthetic characteristics of tropical trees along successional gradients. - In: Mulkey S.S., Chazdon R.L., Smith A.P. (ed.): Tropical Forest Plant Ecophysiology. Pp. 162-186. Springer, Boston 1996.

Swaine M.D., Whitmore T.C.: On the definition of ecological species groups in tropical rain forests. - Vegetatio 75: 81-86, 1988.

Takahashi S., Murata S.: How do environmental stresses accelerate photoinhibition? - Trends Plant Sci. 13: 178-182, 2008.

Teixeira M.C., Trindade F.G., da Cunha M. et al.: Ultrastructural and functional chloroplast changes promoting photoacclimation after forest management in a tropical secondary forest. - Forest Ecol. Manag. 428: 27-34, 2018.

Teixeira M.C., Vieira T.O., Almeida T.C.M., Vitória A.P.: Photoinhibition in Atlantic Forest native species: short-term acclimative responses to high irradiance. - Theor. Exp. Plant Phys. 27: 183-189, 2015.

Valladares F., Gianoli E., Gómez J.M.: Ecological limits to plant phenotypic plasticity. - New Phytol. 176: 749-763, 2007.

Valladares F., Martinez-Ferri E., Balaguer L. et al.: Low leaflevel response to light and nutrients in Mediterranean evergreen oaks: a conservative resource-use strategy? - New Phytol. 148: 79-91, 2000.

Valladares F., Matesanz S., Guilhaumon F. et al.: The effects of phenotypic plasticity and local adaptation on forecasts of species range shifts under climate change. - Ecol. Lett. 17: 1351-1364, 2014.

Valladares F., Niinemets Ü.: Shade tolerance a key plant feature of complex nature and consequences. - Annu. Rev. Ecol. Evol. S. 39: 237-257, 2008.

Valladares F., Sanchez-Gomez D., Zavala M.A.: Quantitative estimation of phenotypic plasticity: bridging the gap between the evolutionary concept and its ecological applications. J. Ecol. 94: 1103-1116, 2006.

van Kleunen M., Fischer M.: Constraints on the evolution of adaptive phenotypic plasticity in plants. - New Phytol. 166: 49-60, 2005

van Kleunen M., Schlaepfer D.R., Glaettli M., Fischer M.: Preadapted for invasiveness: Do species traits or their plastic response to shading differ between invasive and non-invasive plant species in their native range? - J. Biogeogr. 38: 12941304, 2011.

Venables W.N., Ripley B.D.: Modern Applied Statistics with S. Fourth Edition. Pp. 498. Springer, New York 2002.

Vieira T.O., Degli-Esposti M.S.O., Souza G.M. et al.: Photoacclimation capacity in seedling and sapling of Siparuna guianensis (Siparunaceae): response to irradiance gradient in tropical forest. - Photosynthetica 53: 11-22, 2015.

Violle C., Navas M.-L., Vile D. et al.: Let the concept of trait be functional! - Oikos 116: 882-892, 2007

Vitória A.P., Alves L.F., Santiago L.S.: Atlantic forest and leaf traits: an overview. - Trees-Struct. Funct. 33: 1535-1547, 2019.

Vitória A.P., Ávila-Lovera E., Vieira T.O. et al.: Isotopic composition of leaf carbon $\left(\delta^{13} \mathrm{C}\right)$ and nitrogen $\left(\delta^{15} \mathrm{~N}\right)$ of deciduous and evergreen understorey trees in two tropical Brazilian Atlantic forests. - J. Trop. Ecol. 34: 145-156, 2018.

Vitória A.P., Vieira T.O., Camargo P.B., Santiago L.S.: Using leaf $\delta^{13} \mathrm{C}$ and photosynthetic parameters to understand acclimation to irradiance and leaf age effects during tropical forest regeneration. - Forest Ecol. Manag. 379: 50-60, 2016.

Vu V.Q.: ggbiplot: A ggplot2 based biplot. R package version $0.55,2011$.

Weinig C., Delph L.F.: Phenotypic plasticity early in life constrains developmental responses later. - Evolution 55: 930-936, 2001.

Westoby M., Falster D.S., Moles A.T. et al.: Plant ecological strategies: some leading dimensions of variation between species. - Annu. Rev. Ecol. Syst. 33: 125-159, 2002.

Winn A.A.: Adaptation to fine-grained environmental variation: an analysis of within-individual leaf variation in an annual plant. - Evolution 50: 1111-1118, 1996.

Wright I.J., Reich P.B., Westoby M. et al.: The worldwide leaf economics spectrum. - Nature 428: 821-827, 2004.

Wright J.P., Sutton-Grier A.: Does the leaf economic spectrum hold within local species pools across varying environmental conditions? - Funct. Ecol. 26: 1390-1398, 2012.

Wright S.J., Kitajima K., Kraft N.J.B. et al.: Functional traits and the growth-mortality trade-off in tropical trees. - Ecology 91 : 3664-3674, 2010.

Zhang T.J., Zheng J., Yu Z.C. et al.: Variations in photoprotective potential along gradients of leaf development and plant succession in subtropical forests under contrasting irradiances. - Environ. Exp. Bot. 154: 23-32, 2018.

Zimmerman J.K., Ehleringer J.R.: Carbon isotope ratios are correlated with irradiance levels in the Panamanian orchid Catasetum viridiflavum. - Oecologia 83: 247-249, 1990.

(C) The authors. This is an open access article distributed under the terms of the Creative Commons BY-NC-ND Licence. 